\title{
Use of mobile technology in healthcare
}

\author{
Grega Martin Glas, Sara Hafner, Špela Rozman, Andrej Starc \\ University of Ljubljana, Faculty of Health Sciences, Zdravstvena pot 5, 1000 Ljubljana, Slovenia \\ hafner.sara@gmail.com
}

\begin{abstract}
Introduction: It has been shown that ICT (Information Communication Technology) has the potential to provide better healthcare services. In the last decade, mobile technology has become very sophisticated and widely spread among people. It provides a new set of tools to improve the health professional-patient relationship. There have been developed many mobile applications that may be potentially useful for healthcare purposes. The literature review is aimed to present the role of mobile technology in healthcare. Methods: A descriptive research method with a critical review of English scientific and professional literature was performed, using Science Direct, CINAHL with Full Text, MEDLINE, and Google scholar. The keywords with the use of Bool`s operators AND/OR were: smartphones, mobile technology, and healthcare. Literature inclusion criteria were articles published between 2014 and 2019, freely accessible and primarily reviewed articles with clearly defined objectives and methods in the English language. We reviewed 15 articles, the excluded ones did not match our inclusion criteria. The literature search took place in February and March 2020. Data were analyzed using the content analysis method. Results: The results showed that mobile technology can benefit patients as well as healthcare professionals. Patients can use them as devices that help to perform daily tasks for a healthier life or easier management of chronic diseases. Mobile technology can empower the patients, so they can take control of their health condition. Healthcare professionals can use it for additional or different learning options or as a tool in patient-centered care. The use of mobile technology can influence communication and relationship between patients and healthcare professionals, also, it breaks down barriers, such as language and long-distance. Adopting mobile health technology perceived an overall positive impact among patients, indicating they are ready to transition from traditional clinical
\end{abstract}


encounters to modern treatment ways. Nevertheless, caution and professional perspective based on knowledge and ethical considerations are needed when implementing new technology in healthcare. Discussion and conclusions: The use of mobile technology and mobile health interventions has increased significantly. Even though mobile phonebased interventions have the potential to improve treatment outcomes, there are still challenges relating to new technologies that must be taken into consideration. To be able to understand how different factors affect the development process from a technical and human perspective there is a need for evaluation of mobile technology. It is necessary to conduct more studies with greater variety in research design and users on mobile applications to evaluate their effectiveness.

\section{Keywords: smartphones, mobile technology, ICT, healthcare}

\section{Introduction}

Within the last two decades, we have witnessed remarkable technological development of information and communication technologies and their implementation into healthcare (Cannon, 2018). Technological progress has resulted in several movements: a need to address the rising burden of chronic diseases, an exponential increase in developing smaller and cheaper devices, and developing a patient-centered healthcare model. Miniaturization of diagnostic instruments have led to promises to improve patient care, individual well-being, healthcare outcomes, encourage healthy behaviors, reduce healthcare costs and provide widely accessible services (Philips and Merril, 2015; Bhavnani et al., 2016; Aceto et al., 2018).

Mobile health (mHealth) is defined by the practice of medicine that is supported by portable diagnostic services. While technological development offers many benefits, it also raises many ethically relevant questions, regarding widespread device use and their safety (Bhavnani et al., 2016; Lucivero and Jongsma, 2018).

This literature review aims to present the role of mobile technology in healthcare.

\section{Methods}

A descriptive research method with a critical review of English scientific and professional literature was performed, using Science Direct, CINAHL with Full Text, MEDLINE, and Google scholar. The keywords with the use of Bool's operators AND/OR were: smartphones, mobile technology, and healthcare. Literature inclusion criteria were articles published between 2014 and 2019, freely accessible and primarily reviewed articles with clearly defined objectives and methods in English language. We reviewed 15 articles, the excluded ones did not match our inclusion criteria. The literature search 
took place in February and March 2020. Data were analyzed using the content analysis method.

\section{Results}

Through applying our inclusion criteria we were able to find five articles on the use of mobile technology in healthcare. All of the studies are based on a literature review (table 1).

\section{Table 1: Overview of the review studies}

\begin{tabular}{|c|c|c|c|}
\hline $\begin{array}{c}\text { Authors and year } \\
\text { of publication }\end{array}$ & Purpose of research & Methodology & Results \\
\hline $\begin{array}{l}\text { Quadah and } \\
\text { Leutsch, } 2019\end{array}$ & $\begin{array}{l}\text { To explore the influence of } \\
\text { mHealth applications }\end{array}$ & $\begin{array}{l}\text { A systematic, narrative re- } \\
\text { view of literature }\end{array}$ & $\begin{array}{l}\text { mHealth provides bidi- } \\
\text { rectional communication, } \\
\text { regular contact, and con- } \\
\text { tinuous care. It enables } \\
\text { placing the patient at the } \\
\text { center of discussion. }\end{array}$ \\
\hline Grekin et al., 2019 & $\begin{array}{l}\text { To consider mHealth in- } \\
\text { terventions }\end{array}$ & $\begin{array}{l}\text { Literature review and } \\
\text { viewpoint }\end{array}$ & $\begin{array}{l}\text { mHealth reduces barri- } \\
\text { ers, associated with cost, } \\
\text { transportation, and treat- } \\
\text { ment-related stigma. }\end{array}$ \\
\hline $\begin{array}{l}\text { Hallberg et al., } \\
202 \mathrm{O}\end{array}$ & $\begin{array}{l}\text { To describe the develop- } \\
\text { ment and evaluation of } \\
\text { mHealth }\end{array}$ & Literature review & $\begin{array}{l}\text { Evaluation on how various } \\
\text { factors affect the develop- } \\
\text { ment process from both a } \\
\text { technical and human per- } \\
\text { spective is important. }\end{array}$ \\
\hline Nouri et al., 2018 & $\begin{array}{l}\text { To assess the quality of } \\
\text { mHealth apps }\end{array}$ & Literature review & $\begin{array}{l}\text { Assessment criteria for de- } \\
\text { vices evaluation: design, } \\
\text { information/content, usa- } \\
\text { bility, functionality, ethical } \\
\text { issues, security and privacy } \\
\text { and user-perceived value. }\end{array}$ \\
\hline $\begin{array}{l}\text { Lucivero and Jong- } \\
\text { sma, } 2018\end{array}$ & $\begin{array}{l}\text { To overview bioethical is- } \\
\text { sues raised by mHealth }\end{array}$ & Literature review & $\begin{array}{l}\text { Developers of the devic- } \\
\text { es need to ensure that they } \\
\text { will be used only for the } \\
\text { intended purpose, in cer- } \\
\text { tain contexts. }\end{array}$ \\
\hline $\begin{array}{l}\text { Birkhoff and } \\
\text { Smeltzer, } 2017\end{array}$ & $\begin{array}{l}\text { To describe the experienc- } \\
\text { es of mHealth applications } \\
\text { among chronic disease } \\
\text { populations }\end{array}$ & $\begin{array}{l}\text { Integrative review of the } \\
\text { literature }\end{array}$ & $\begin{array}{l}\text { User-centered mHealth } \\
\text { provides individualized } \\
\text { support to chronic illness } \\
\text { populations. }\end{array}$ \\
\hline
\end{tabular}

\section{Discussion}

The problem of the doctor-patient relationship in the form of depersonalization arises due to the absence of face-to-face interaction, nonverbal communication, and the opportunity to observe the patient (Quadah and Leutsch, 2019). Patients are burdened with professional tasks they are not qualified for (Lucivero and Jongsma, 2015; Cvirkel, 2018).

Mobile technology has the potential to provide services to areas and people that are difficult to reach. Those kinds of services may not reach the ones 
who are most in need of care, due to lack of mobile phones, internet connection, low-income, and elderly people (Chib et al., 2014; Lucivero and Jongsma, 2015).

New revolutionary devices need to be assessed carefully concerning their plausibility (Lucivero and Jongsma, 2015). There are still many uncertainties, including the selection of appropriate devices, privacy and security issues, the lack of evaluation standards, limited quality control, and the pressure to move into the mainstream of healthcare (Noouri et al., 2018). Possibilities for abuse of sensitive health information and unforeseen effects need to be explored (Lucivero and Jongsma, 2015).

\section{Conclusions}

In the next decade, we expect even greater convergence of technology and healthcare, resulting in the development of new technologies. To achieve the potential of mobile technology in healthcare, we have to identify methods for patient engagement, to develop the necessary tools to streamline clinical integration and data analytics, and to outline the regulatory factors. There is a need to evaluate which patients are suitable for device-based self-care. Mobile technology is argued to be an efficient and cost-effective solution for prevention, monitoring, and management. Technical and ethical concerns arise, which demands structured verification and evaluation of mobile technology and the clinical impact of these technologies, due to overly positive promises.

\section{References}

ACETO, G., PERSICO, V. and PESCAPE, A., 2018. The role of information and communication technologies in healthcare: taxonomies, perspectives, and challenges. Journal of Network and Computer Applications, vol. 107, pp. 125-154. Available from: https://doi.org/10.1016/j.jnca.2018.02.008

BHAVNANI, S., NARULA, J. and SENGUPTA, P.P., 2016. Mobile technology and the digitization of healthcare. European Heart Journal, vol. 37, no. 18, pp. 1428-1438. Available from: https://doi.org/10.1093/eurheartj/ehv770

BIRKHOFF, S.D. and SMELTZER, S.C., 2017. Perceptions of smartphone user-centered mobile health tracking apps across various chronic illness populations: an integrative review. Journal of Nursing Scholarship, vol. 49, no. 4, pp. 1-8. Available from: https://doi.org/10.1111/jnu.12298

CANNON, C., 2018. Telehealth, mobile applications and wearable devices are expanding cancer care beyond walls. Seminars in Oncology Nursing, vol. 34, no. 2, pp. 118-125. Available from: https://doi.org/10.1016/j.soncn.2018.03.002

CHIB A., HELENA M. and CAR J., 2014. mHealth adoption in low-resource environments: a review of the use of mobile healthcare in developing countries. Journal of Health Communications, vol. 20, no. 1, pp. 1-31. Available from: https://doi.org/10.1080/10810730.2013.864735 
CVIRKEL, T., 2018. The ethics of mHealth: moving forward. Journal of Dentistry, vol 74, pp. S15-S20. Available from: https://doi.org/10.1016/j. jdent.2018.04.024

DENiS, F., LETHROSNE, C., POUREL, N., MOLINIER, O., POINTREAU, Y., DOMONT, J., BOURGEOIS, H.P., SENELLART, H., TREMOLIERES, P., LIZEE, T., et al., 2016. Overall survival in patients with lung cancer using a web-application-guided follow-up compared to standard modalities: Results of phase III randomized trial. Journal of Clinical Oncology, vol. 34, no. 18. Available from: https://ascopubs.org/doi/abs/10.120o/JCO.2016.34.18_suppl. LBA9006

GREKIN, E.R., BEATTY, J.R. and ONDERSMA, S.J., 2019. Mobile health interventions: exploring the use of common relationship factors. JMIR mHealth uHealth, vol. 7, no. 4, pp. e11245. Available from: https://doi.org/10.2196/11245

KOIVUNEN, M. and SARANTO, K., 2018. Nursing professionals' experiences of the facilitators and barriers to the use of telehealth applications: a systematic review of qualitative studies. Scandinavian Journal of Caring Sciences, no. 32, pp. 24-44. Available from: http://dx.doi.org.nukweb.nuk.uni-lj.si/10.1111/ SCS.12445.

LUCIVERO, F. and JONGSMA K.R., 2018. A mobile revolution for healthcare? Setting agenda for bioethics. Political philosophy and medical ethics, vol. 44, no. 10, pp. 1-5. Available from: https://doi.org/10.1136/medethics-2017-104741

NOURI R., NIAKAN KALHORI S.R., GHAZI SAEEDI M., MARCHAND G. and YASINI M., 2018. Criteria for assessing the quality of mHealth apps: a systematic review. Journal of the American Medical Informatics Association, vol. 25, no. 8, pp. 1089-1098. Available from: https://doi.org/10.1093/jamia/ ocyo50

PHILIPS, A.B. and MERRILL, J.A., 2018. Innovative use of the integrative review to evaluate evidence of technology transformation in healthcare. Journal of Biomedical Informatics, no. 58, pp. 114-121. Available from: http://dx. doi.org/10.1016/j.jbi.2015.09.014

QUDAH, B. and LUETSCH, K., 2019. The influence of mobile health applications on patient - healthcare provider relationships: a systematic, narrative review. Patient Education and Counseling, vol. 102, no. 6, pp. 1080-1089. Available from: https://doi.org/10.1016/j.pec.2019.01.021 